\title{
Estratégia neuropedagógica computacional para promover o desenvolvimento de jovens em áreas de risco e vulnerabilidade social
}

Ana Paula Cavadas Rodrigues ${ }^{3}$, Raquel Moreira Machado Fernandes ${ }^{1,2}$, Claudia Lage Rebello da Motta ${ }^{1,3}$, Carla Verônica Machado Marques ${ }^{3}$, Carlo Emmanoel Tolla de Oliveira ${ }^{3}$

\author{
${ }^{1}$ Programa de Pós Graduação em Informática da Universidade Federal do Rio de \\ Janeiro \\ ${ }^{2}$ Universidade Federal Fluminense \\ ${ }^{3}$ Instituto Tércio Pacitti de Aplicações e Pesquisas Computacionais da Universidade \\ Federal do Rio de Janeiro
}

\begin{abstract}
anapcavadas@gmail.com,raquelmachado@id.uff.br,claudiam@nce.ufrj.br, carlaveronica@nce.ufrj.br,carlo@nce.ufrj.br
\end{abstract}

Abstract. This article presents a computational neuropedagogical strategy based on digital fluency + knowledge sharing, where digital fluency is driven by the construction of intelligent games and the sharing of knowledge promotes the cognitive development and social action of elementary school students from a ocality of risk and social vulnerability. Through this strategy the students of the sample presented a socio-cognitive development and created a game called Radical Garden

Resumo. Este artigo apresenta uma estratégia neuropedagógica computacional baseada no binômio fluência digital + compartilhamento de saberes, onde a fluência digital é impulsionada pela construção de games inteligentes e o compartilhamento de saberes promove o desenvolvimento cognitivo e a atuação social de estudantes do ensino fundamental oriundos de uma localidade de risco e vulnerabilidade social. Através dessa estratégia os estudantes da amostra apresentaram indícios de desenvolvimento sociocognitivo e criaram um game chamado Jardim Radical.

\section{Introdução}

Crianças que vivem em áreas de alta vulnerabilidade social, apesar de serem nativas digitais, não são fluentes digitais, pois entram para escola sem saber utilizar e se expressar através das tecnologias. Essas crianças estão sujeitas a uma educação que utiliza métodos ultrapassados, onde o foco está na memorização. Este artigo apresenta uma pesquisa que teve como objetivo investigar possibilidades de modificar a realidade dessas crianças e adolescentes. Como isto seria possível sem a oportunidade de desenvolvimento e preparo para um mercado cada vez mais imbuído de tecnologia? Esses estudantes precisam de uma educação que valorize a autonomia e a criatividade. É preciso levar a tecnologia para o quotidiano dessas crianças através de um processo que lhes permita a apropriação das mesmas, como sujeitos ativos. 
Com o foco no segundo segmento do ensino fundamental e ensino médio, identificou-se que trabalhar com o ensino de programação seria uma possibilidade promissora. Contudo, Marques [2011] alerta sobre os altos índices de reprovação em disciplinas que envolvam a programação, além da crescente evasão nesses cursos. É necessário, portanto, utilizar um fator motivacional. Neste trabalho utilizamos uma abordagem de construção de jogos denominados games inteligentes; a abordagem é baseada em princípios neurocientíficos que viabilizam através da construção do pensamento computacional e da investigação científica, um modelo único que possibilita ao estudante "aprender a aprender", criando, desta forma, um canal para viabilizar a metacognição. Foram seguidas as etapas de elaboração dos games inteligentes, como descritas por Marques [2015]. Essa metodologia envolve quatro grandes processos: modelagem dimensional, processo criativo, projeto interacional e desenvolvimento conceitual. Para a elaboração do game, utilizamos conceitos neurocientíficos com embasamento nas pesquisas de Inhelder [1997], Bandura [2008], Seminério [1979], Guilford [1967] e Marques [2017].

A criação de uma estratégia neuropedagógica de aprendizado com abordagem metacognitiva associada ao ensino de programação de games utilizando a linguagem Python se mostrou uma estratégia bem-sucedida uma vez que permitiu que estudantes participantes do processo se tornassem, em um segundo momento, multiplicadores do processo da elaboração dos games. Para tanto, foi feita uma adaptação do processo de desenvolvimento de software, transformando-o em uma abordagem pedagógica para possibilitar ao estudante, através das etapas de criação dos games inteligentes, dar saltos cognitivos e torná-lo apto a construir ferramentas para sua própria educação.

Este modelo já está sendo aplicado há três anos. Os estudantes que participaram do projeto e que já estão no ensino médio atualmente são bolsistas do Programa Institucional de Bolsas de Iniciação Científica do Ensino Médio, atuando como instrutores de programação de games inteligentes para os estudantes do ensino fundamental.

A pesquisa de caráter bibliográfico que embasou este projeto foi de caráter interdisciplinar, abrangendo pesquisadores das áreas de Psicologia, Neuropedagogia Computacional, Biologia, Linguística, entre outras áreas de conhecimento.

\section{Desafios}

A escola onde foi realizada essa pesquisa e onde o projeto ainda ocorre está localizada no bairro de Costa Barros, aos pés da comunidade conhecida como Complexo da Pedreira, região que engloba alguns bairros que reúnem os índices de desenvolvimento humano $\left(\mathrm{IDH}^{1}\right.$ e IDS $^{2}$ ) mais baixos de toda a cidade do Rio de Janeiro. Os bairros de Costa Barros, Acari, Barros Filho, Coelho Neto e Pavuna estão no último terço do ranking dos IDH's dos bairros cariocas, estando alguns deles, figurando entre os bairros

1 Dados disponíveis em https://pt.wikipedia.org/wiki/Lista_de_bairros_do_Rio_de_Janeiro_por_IDH. Dados do ano de 2000, a partir do Censo ocorrido no referido ano.

${ }^{2}$ Com base nos dados do estudo "Índice de Desenvolvimento Social - IDS: comparando as realidades micro urbanas da cidade do Rio de Janeiro", de Fernando Cavallieri e Gustavo Peres Lopes IPP/Prefeitura da cidade do Rio de Janeiro - Abril, 2008. 
VIII Congresso Brasileiro de Informática na Educação (CBIE 2019)

Anais do XXV Workshop de Informática na Escola (WIE 2019)

de pior índice, como Costa Barros e Acari (penúltimo e antepenúltimo bairros da referida lista).

O entorno da escola possui condições precárias, como exemplo, cita-se: moradias precárias, falta de asfalto, poluição, degradação do rio Acari, cuja escola localiza-se às margens, presença ostensiva de traficantes armados, entre outros. A escola é uma das poucas referências de atuação constante do poder público em uma localidade que reúne tantas mazelas. Esse quadro interfere diretamente no processo de ensino/aprendizagem dos estudantes, já que quase a totalidade deles mora próximo à escola, bem como em outras favelas do Complexo da Pedreira.

A escola apresenta uma boa infraestrutura, pois foi fundada em 2012 e dispõe de ar condicionado e projetores em todas as salas de aula. Os maiores desafios se concentram em oferecer uma educação gratuita e de qualidade numa região da cidade tão carente e violenta. Essa carência engloba os mais diversos campos, como financeiro, sentimental, falta de opções de lazer e cultura, ou mesmo de condições mínimas de cidadania, tanto para os estudantes, como aos moradores de toda a região.

Os índices de evasão escolar, de reprovação e de distorção idade-série da Daniel Piza são considerados altos em comparação a outras escolas localizadas na cidade do Rio de Janeiro $(7,5 \%, 10,7 \% \text { e } 37,2 \% \text {, respectivamente })^{3}$. O panorama descrito é fundamental para entender alguns dos muitos desafios encontrados para 0 desenvolvimento e manutenção desse trabalho.

\section{Metodologia}

Essa pesquisa propõe uma estratégia neuropedagógica computacional baseada no binômio fluência digital + compartilhamento de saberes, onde a fluência digital é impulsionada pela construção de games inteligentes e o compartilhamento de saberes promove o desenvolvimento cognitivo.

A condução da pesquisa foi através da metodologia de pesquisa-ação. Os estudantes do segundo segmento do ensino fundamental e os estudantes do ensino médio desenvolveram de forma colaborativa um jogo computacional denominado Jardim Radical, que é um instrumento de coleta e intervenção. O caráter científico do processo de construção deste jogo garante a sua eficácia como instrumento de medida e intervenção mental. Os estudantes receberam formação básica em Informática, Neuropedagogia Computacional e desenvolvimento de software. Como metodologia de concepção, utilizou-se a proposta de desenvolvimento de games inteligentes [Marques, 2017]. Para alcançar esse objetivo foram aplicadas durante os encontros técnicas que possuem um embasamento neurocientífico como o Fio Condutor Técnico Pedagógico, a Elaboração Dirigida e o estímulo ao Pensamento Computacional.

\subsection{Estratégia neuropedagógica computacional}

Esta pesquisa tem o intuito de apresentar uma estratégia inovadora não só para a produção de games inteligentes, mas para o desenvolvimento de uma educação

\footnotetext{
${ }^{3}$ Informação retirada do estudo de indicadores sociais realizado pelo INEP, referente ao ano de 2016. Disponível em http://portal.inep.gov.br/indicadores-educacionais . Acesso em 28 Jul 2017.
} 
VIII Congresso Brasileiro de Informática na Educação (CBIE 2019)

Anais do XXV Workshop de Informática na Escola (WIE 2019)

científica, que segundo Paulo Freire [1967] é aquela que possibilita a participação na tomada de decisões de forma crítica, possuindo a compreensão dos processos da ciência e da tecnologia no mundo atual. Nesse sentido, a técnica do Fio Condutor Técnico Pedagógico, surgiu de uma adaptação do Fio Condutor Técnico descrito por Marques [2009]. Esta adaptação fornece um acréscimo à base de conhecimento científica existente e possibilita reflexões que vão ao encontro do pensamento científico. O Fio Condutor Técnico Pedagógico possui cinco fases, explicitadas a seguir:

\section{- FASE 0 - Povoamento do Imaginário-Intervenção}

Para tratar desse problema, iniciou-se um estudo sobre a importância do desenvolvimento do processo criativo, utilizando como embasamento $O$ imaginário cognitivo: uma fronteira entre consciência e inconsciente, de Franco Lo Presti Seminerio [1997]. O artigo aponta uma estrutura de desenvolvimento do imaginário a partir de um dispositivo cognitivo inato, que é construído sobre os insumos de um real incognoscível. Após diversas verificações em laboratório, Seminério apresenta a existência de quatro "linguagens-códigos" hierarquizadas nos canais visomotor e áudio fonéticos: a L1-Percepção, L2-Vocabulário, L3- Imaginário e L4-Lógica. Nessa fase do Fio Condutor Técnico Pedagógico, foi priorizado o desenvolvimento do imaginário, ou seja, linguagem L3. Para tanto, os estudantes foram levados semanalmente a diversos ambientes, tais como: sala de leitura, sala de informática, laboratório de ciências e passeios ao Jardim Botânico do Rio de Janeiro de onde foram retiradas fotos pelos próprios estudantes para composição do cenário do game.

\section{- FASE 1 - Apresentação dos Elementos Desconexos do ORC - Estimulação-Ação}

No intuito de recrutar funções executivas, durante as aulas de games, foi apresentado um problema no qual o estudante era estimulado a buscar a solução. Tal problema é denominado Objeto Real do Conhecimento (ORC), descrito por Marques [2009]. Nesta fase, apresentam-se os elementos desconexos do (ORC), como materiais para o experimento dispostos na bancada do laboratório e nas aulas de informática, como o computador e a programação. Nesse momento é aplicado o pensamento computacional, ou seja, é recrutado dos estudantes um conjunto de competências para a solução de problemas [Brackmann, 2017].

Destaca-se também o processo de formalização do pensamento, que tem, segundo Piaget [1976], a maturação biológica, seguida de processos de interação com o meio, originando estágios universais do desenvolvimento. Segundo Costa et.al. [2013], Papert descreve que "além da maturação biológica essas etapas também são determinadas por materiais disponíveis no ambiente para a exploração do estudante, e que esse processo se intensifica à medida que o conhecimento se torna fonte de poder para ele" [Papert, 1986 apud Costa, 2013]

A partir do momento em que o estudante conecta as partes do ORC para criação do game, ele inicia o entendimento e a formação de um novo conhecimento, praticando, dessa forma, o construcionismo, termo descrito por Papert [1994] como sendo o desenvolvimento do aprendizado por meio da construção ou criação de algo. 
VIII Congresso Brasileiro de Informática na Educação (CBIE 2019)

Anais do XXV Workshop de Informática na Escola (WIE 2019)

\section{- FASE 2 - Expressão-Interpretação-Verbalização}

Nesta fase o professor pergunta ao estudante: Por que você realizou dessa forma?

Para a psicologia moderna, a fala é um meio especial de comunicação que usa a linguagem para a transmissão de informações. A fala é uma forma complexa e especificamente organizada de atividade consciente que envolve a participação do indivíduo que formula a expressão falada e a do indivíduo que a recebe.

Tratando-se dos mecanismos da fala, Luria [1981] descreve a fala expressiva e a fala impressiva, que trabalham em mecanismos sequenciais e, por vezes, concomitantes. Em se tratando deste trabalho, tem início a fala impressiva quando o estudante observa os materiais desconexos dispostos na bancada do laboratório, ou quando está em frente ao computador para desenvolvimento de uma determinada tarefa. A fala expressiva tem início com a observação do material exposto, que é reunida em um esquema de fala e posta em operação com o auxílio da fala interna; então formam esquemas que são convertidos em fala narrativa.

\section{- FASE 3 - Intervenção-Interpretação-Nova Construção}

O professor pergunta: Se mudar esses componentes, o resultado será o mesmo?

Para este trabalho, para interpretação dos estudantes perante os problemas propostos, foram utilizados também os prognósticos estabelecidos de acordo com a transitividade entre as áreas de linguagem, matemática e ciências, descritos por Marques [2017].

Criou-se uma inter-relação do binômio Age-Interpreta de Seminério e os prognósticos descritos por Marques [2017]. Ainda segundo esta autora, o prognóstico consiste em quatro modelos cognitivos: Verdadeiro Sucesso (VS), Sucesso Mínimo (SM), Falso Sucesso (FS) e Exclusão Simbólica (ES), apresentando-se da forma representada na Figura 1.

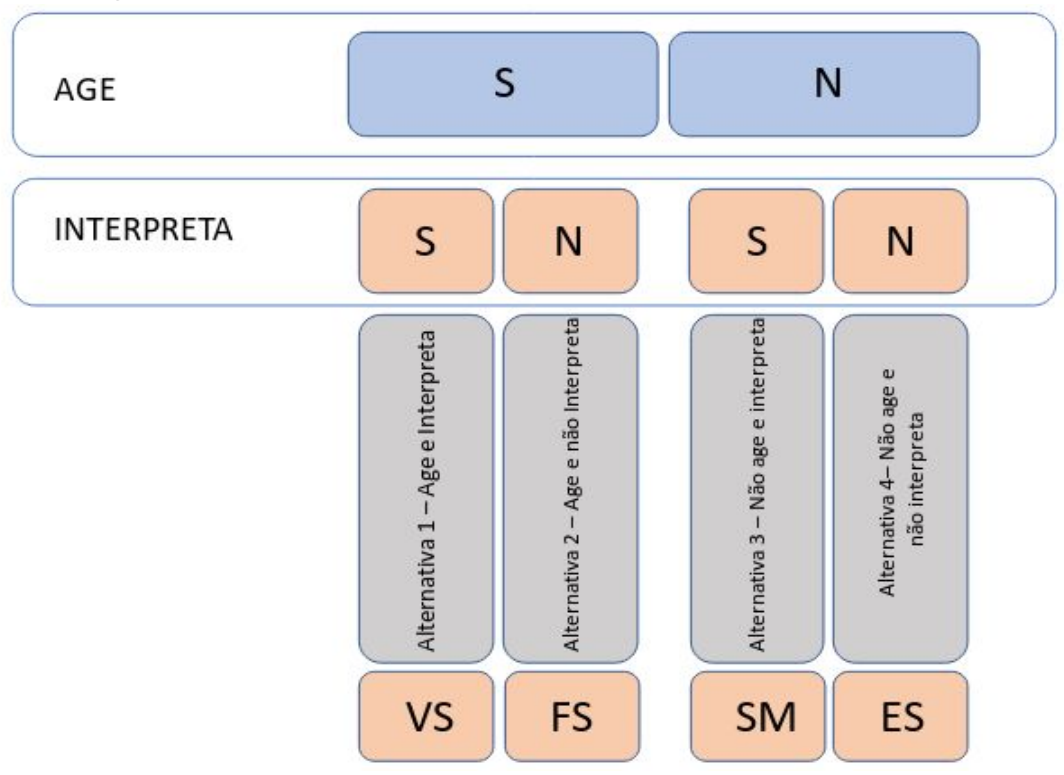

Figura 1 - Age-Interpreta de Seminério e os prognósticos descritos por Marques [2017] 
VIII Congresso Brasileiro de Informática na Educação (CBIE 2019)

Anais do XXV Workshop de Informática na Escola (WIE 2019)

\section{- FASE 4 - Intervenção- Transitividade em diversas áreas do conhecimento-Avaliação}

O professor pergunta: “O que você fez? Esse conhecimento é aplicado apenas nessa disciplina?"

Agora transmita esse conhecimento para outros grupos.

No Fio Condutor Técnico-pedagógico, também foram utilizados conceitos sobre Grupo Operativo de Enrique Pichon Rivière, psiquiatra e psicanalista suíço nacionalizado argentino, que designa grupo operativo como o constituído de pessoas reunidas com o objetivo comum, chamado de grupo centrado na tarefa. Tal grupo tem por objetivo aprender a pensar em termos de resolução das dificuldades criadas e manifestadas no campo grupal. Nesse grupo, cada membro tem um papel específico a ser atribuído, porém podendo assumir outros papéis funcionais durante o processo; esses papéis podem ser assumidos previamente ou não. No caso deste trabalho, os papéis foram assumidos antecipadamente, pois os líderes do grupo seriam os estudantes que haviam chegado ao conhecimento do Objeto Real do Conhecimento de forma satisfatória.

Em todas as fases do Fio Condutor Técnico Pedagógico foram aplicadas a técnica da Elaboração Dirigida e o estímulo ao Pensamento Computacional. O primeiro item é uma estratégia de modulação experimental que visa provocar a descoberta do metaprocesso por meio da atividade discursiva e reflexiva de estimulação do estudante. O segundo trata-se uma distinta capacidade criativa, crítica e estratégica humana de saber utilizar os fundamentos da Computação, nas mais diversas áreas do conhecimento, com a finalidade de identificar e resolver problemas, de maneira individual ou colaborativa, através de passos claros, de tal forma que uma pessoa ou uma máquina possam executá-los eficazmente [Kurshan, 2016].

\section{Construção do Game Jardim Radical}

No modelo dimensional dos games inteligentes foram trabalhadas três dimensões: Afetividade, Teoria da Evolução e Taxonomia de Bloom. A primeira dimensão tem como base os estudos de Henry Wallon e a segunda tem como base os teóricos Charles Robert Darwin e Richard Dawkins. Já, a última dimensão baseia-se em Ferraz [2010], entre outros.

Para os estudantes serem capazes de elaborar enredos com as dimensões descritas acima, que dariam origem ao crivo computacional - que é o conjunto de atitudes computacionais frente a um problema, descrito no GDD (Game Design Document) do game, foram realizadas por eles pesquisas sobre estas dimensões e depois foram elencados pelos estudantes os itens mais importantes. Dando prosseguimento ao desenvolvimento do GDD, foram escolhidos cenários, personagens, objetos além da criação das histórias do game Jardim Radical.

Para avaliação da Afetividade foram criadas situações disponibilizadas a cada jogada, que podem ou não afetar o jogador. Já no caso da Teoria da Evolução foram avaliadas situações a partir da Taxonomia de Bloom. Estas medidas de avaliação são colocadas durante a criação do conteúdo narrativo do game, no caso deste trabalho os enredos do jogo que deram origem aos takes. O enredo é o conjunto das ações 
VIII Congresso Brasileiro de Informática na Educação (CBIE 2019)

Anais do XXV Workshop de Informática na Escola (WIE 2019)

executadas pelos personagens no jogo, a fim de criar sentido ou emoção no espectador. É usado para estruturar todos os eventos que acontecerão no jogo.

O game se propõe a coletar dados sobre o conhecimento cognitivo do jogador sobre a Teoria da Evolução, e a afetividade, a partir de marcadores computacionais, que verificam atitudes do jogador a partir de axiomas descritos no crivo computacional.

Os itens que foram escolhidos pelos estudantes para avaliar o conhecimento dos futuros jogadores acerca da Teoria da Evolução estão representado na Tabela 1.

Tabela 1: Crivo Computacional

\begin{tabular}{|c|c|c|c|}
\hline Axioma Afetividade & Teoria da Evolução & $\begin{array}{l}\text { Taxonomia de } \\
\text { Bloom }\end{array}$ & Jogadas (Takes) \\
\hline \begin{tabular}{l}
\multicolumn{3}{c}{ Sensibilidade } \\
-...sinalizadores de \\
como o ser humano \\
é afetador pelo \\
mundo interno e \\
externo (pág.17) \\
-Afetividader se \\
origina \\
sensibilidades das \\
orgânicas \\
primitivas, \\
denominadas \\
sensibilidade \\
interoceptiva \\
proprioceptiva, que \\
juntamente com os \\
automatismos, são \\
vistas por Wallon \\
como recursos que \\
a criança tem para \\
se comunicar e \\
sobreviver.
\end{tabular} & 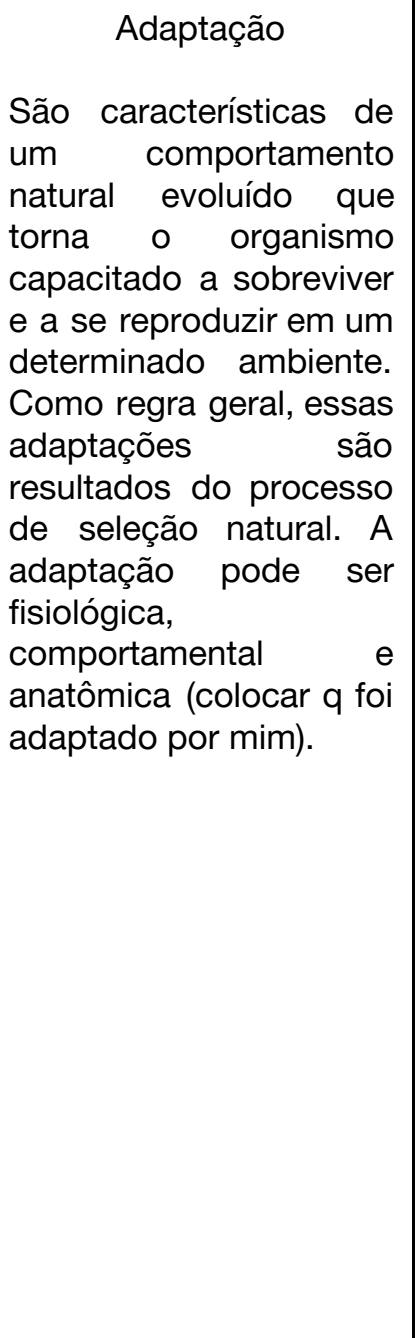 & \begin{tabular}{lr}
\multicolumn{3}{c}{ Lembrar } \\
Relacionado a \\
reconhecer \\
reproduzir ideias e \\
conteúdos. \\
Reconhecer \\
requer distinguir e \\
selecionar uma \\
determinada \\
informação \\
reproduzir e \\
recordar está mais \\
relacionado \\
busca por una \\
informação \\
relevante \\
memorizada. \\
(Ferraz, 2010)
\end{tabular} & $\begin{array}{l}\text { Take 1 } \\
\quad \text { Dimensões: } \\
\text { Sensibilidade, } \\
\text { adaptação e lembrar } \\
\quad \text { Moedas pelo } \\
\quad \text { chão } \\
\quad \text { Passarinho } \\
\quad \text { caído } \\
\text { companheiro do } \\
\text { jogador perna } \\
\text { machucada } \\
\text { Bengala sob a pedra } \\
\text { Surge } \\
\text { Darwin-assombrando. } \\
\text { Pegam a bengala e } \\
\text { correm. } \\
\text { Sentem fome } \\
\text { Frutas pelo chão } \\
\text { Pássaros comem } \\
\text { algumas frutas } \\
\text { Comem as frutas que } \\
\text { os pássaros comem } \\
\text { Surge o Sr. Macaco } \\
\text { Procuram guarita } \\
\text { Itens encontrados: } \\
\text { moedas, bengala de } \\
\text { Darwin, } \\
\text { Obstáculo: pedra } \\
\text { NPC: Sr. Macaco } \\
\text { ? }\end{array}$ \\
\hline
\end{tabular}

A Teoria da Evolução é avaliada pela Taxonomia de Bloom e a afetividade a partir do comportamento do jogador perante uma jogada, objeto ou adversário. A Taxonomia de Bloom é baseada no princípio e na importância de utilizar o conceito de classificação como forma de se estruturar e organizar um processo de aprendizagem. 
Abrange três domínios: o cognitivo, relacionado a aprender e a dominar um conhecimento, que apresenta seis subcategorias, do mais simples para o mais complexo, que são lembrar, entender, aplicar, analisar, avaliar e criar.

\section{Resultados e Discussão}

A fim de testar se a metodologia de desenvolvimento de games inteligentes propiciava um desenvolvimento da cognição a nível de metacognição, ou seja, de "aprender a aprender" para os estudantes envolvidos, foi iniciado o jogo computacional denominado Jardim Radical. Para testar essas possibilidades foi solicitado aos envolvidos elencar os itens mais importantes e suas respectivas definições sobre a Teoria da Evolução e Afetividade, que fariam parte do crivo computacional. Os estudantes envolvidos foram capazes não só de elencar os itens, mas de dispor de definições satisfatórias sobre os itens elencados. Além disso, conseguiram criar histórias e ligar as três dimensões propostas para o game, ou seja, Afetividade, Teoria da Evolução e Taxonomia de Bloom, indo até a categoria mais complexa da Taxonomia de Bloom.

O desenvolvimento do game é, portanto, uma prática pedagógica que recruta dos estudantes a capacidade de criação de regras, além do domínio conceitual das dimensões do game para elaborar as jogadas, o que os leva à metacognição.

As aulas de programação em Python constituíram uma forma de aprendizado lúdica e prazerosa, com apoio dos discentes de graduação da equipe do Laboratório da Universidade Federal do Rio de Janeiro, de modo que os estudantes pudessem realizar a programação do jogo.

Como contribuições tecnológicas para os processos de ensino e de aprendizagem, cita-se o desenvolvimento da lógica e do pensamento computacional para os estudantes da amostra privilegiada, bem como a fluência digital possibilitada pela apropriação das tecnologias para produção do jogo.

Durante a produção do jogo, como resultado direto dos procedimentos adotados nas atividades, destaca-se a confirmação da possibilidade de estimular o raciocínio científico e a perspectiva de levar o conhecimento das ciências biológicas de forma interativa, lúdica e colaborativa através do pensamento computacional, da utilização e da produção de jogos de acordo com uma metodologia científica.

Outro resultado importante deste trabalho é o empoderamento dos estudantes envolvidos, o que ocasionou superação da dependência social, além do desenvolvimento da autonomia.

Os estudantes envolvidos no processo tornaram-se multiplicadores de games inteligentes, apresentando o trabalho em semanas científicas da Universidade Federal do Rio de Janeiro. Atualmente são monitores de duas turmas de games inteligentes na Escola Municipal Jornalista e Escritor Daniel Piza e recentemente se apresentaram no evento Python Sudeste, realizado por uma comunidade de programadores e entusiastas da linguagem Python. 
VIII Congresso Brasileiro de Informática na Educação (CBIE 2019)

Anais do XXV Workshop de Informática na Escola (WIE 2019)

\section{Conclusões}

A partir de um estudo sobre as avaliações escritas e orais realizadas durante todo o processo, observa-se que os estudantes não gostam de aulas expositivas, e quando avaliados, segundo a Taxonomia de Bloom, estão no domínio cognitivo do verbo lembrar, em relação às aulas expositivas. Chegou-se a essa conclusão, realizando-se perguntas pertinentes ao tema dado em aula uma semana depois, onde mesmo os alunos conceituados como MB (muito Bom) e B (Bom), não conseguiam responder as perguntas acima do nível de conhecimento da Taxonomia de Bloom. A maioria da turma sequer lembrava-se do conteúdo exposto. Na avaliação que abrangeu a elaboração do enredo do game, constatou-se que os estudantes conseguiram criar histórias até o último domínio cognitivo que é o domínio criar, fato comprovado durante as aulas de elaboração das histórias.

A criação do game pelos próprios estudantes se transformou em um estímulo interno, gerando um sentimento de autoeficácia, descrito por Bandura [2008]. Assim, os estudantes se sentiram competentes ao construírem algo que não haviam tentado antes. Além disso, deve-se levar em conta o processo de modelagem descrito por Bandura, onde a aprendizagem se dá a partir de modelos e de imitação. Sendo assim, o maior tempo de convivência com a professora, a coexistência em ambientes distintos da comunidade e da escola, com pessoas diferentes, bem como passar por processos de letramento digital adquirindo fluência digital, com uma participação social, produziu uma modificação comportamental, aumentando a expectativa dos estudantes com relação ao seu próprio futuro.

Sendo assim, a fluência digital possibilitada pela construção de jogos e pelo compartilhamento de saberes constitui um novo modelo de aprendizagem com uma grande contribuição da tecnologia para impulsionar cada vez mais a Educação.

\section{Agradecimentos}

Agradecimentos à Escola Municipal Charles Anderson Weaver, à Escola Municipal Jornalista e Escritor Daniel Piza e ao Programa de Pós Graduação em Informática (PPGI) da Universidade Federal do Rio de Janeiro.

\section{Referências}

Bandura, A., Azzi, R.G., Polydoro, S. (2008) "A evolução da teoria social cognitiva, Teoria social cognitiva: conceitos básicos”. Porto Alegre: Artmed: 15-41.

Brackmann, C. P. (2017) "Desenvolvimento do pensamento computacional através de atividades desplugadas na educação básica", Universidade Federal do Rio Grande do Sul.

Cox, K. K. e Bittencourt, R.A. (2017) "Estudo Bibliográfico sobre o Processo de Construção de Jogos Digitais: A Necessidade de Sinergia entre o Educar e o Divertir." Revista Brasileira de Informática na Educação-RBIE 25.1.

Darwin, C. (2005) “A origem das espécies”, Lelo \& Irmão.

Darwin, R. (2008) "O gene egoísta", Trad. Rejane Rubino, Editora Schwarz Ltda 
VIII Congresso Brasileiro de Informática na Educação (CBIE 2019)

Anais do XXV Workshop de Informática na Escola (WIE 2019)

Almeida, L. R. e Mahoney, A.A. (2004) “Constituição da pessoa na proposta de Henri Wallon", Edições Loyola.

Ferraz, A. P. C. M. e Renato R.V. (2010) "Taxonomia de Bloom: revisão teórica e apresentação das adequações do instrumento para definição de objetivos instrucionais." Gest. Prod., São Carlos 17.2: 421-431.

Freire, P. (1967) “Educação como prática de liberdade”. Rio Janeiro, Ed. Paz e Terra.

Guilford, Joy Paul. (1967) "The nature of human intelligence", McGraw-Hill

Inhelder, B., Cellérier G. e Gruman, E. (1996) "O desenrolar das descobertas das crianças: um estudo sobre as microgêneses cognitivas”, Artes Médicas

Kreimeier, B. (2002) "The case for game design patterns", https://www.gamasutra.com/view/feature/132649/the_case_for_game_design_patter ns.php, acessado em: 17 de agosto de 2017.

Marques, C.V.M; Motta, C.R.L da; Oliveira, C. E. T. de.(2009) “ A revolução cognitiva: um estudo sobre a teoria de Franco Lo Presti Seminério". Relatório técnico NCE, n. 0409.

Marques, D. L et al. (2011) "Atraindo alunos do ensino médio para a computação: Uma Experiência Prática de Introdução à Programação utilizando Jogos e Python”. Anais do Workshop de Informática na Escola. p. 1138-1147.https://www.gamasutra.com/view/feature/132649/the_case_for_game_de sign_patterns.php

Marques, C. V. M., Nogueira, E. C. e Brasil, G. (2015) "Game Inteligente: conceito e aplicação." Anais do Seminário de Jogos Eletrônicos, Educação e Comunicação 1.1

Marques, C. V. M. (2017) "Eica - Estruturas Internas Cognitivas Aprendentes: Um Modelo Neuro-Computacional Aplicado À Instância Psíquica Do Sistema Pessoa Em Espaços Dimensionais”. Universidade Federal do Rio de Janeiro.

Morais, F. et al. (2017) "Computação Afetiva aplicada à Educação: uma revisão sistemática das pesquisas publicadas no Brasil”. In: Brazilian Symposium on Computers in Education (Simpósio Brasileiro de Informática na Educação-SBIE).. p. 163- XXX.

Papert, Seymour M. (1994). A Máquina das Crianças: Repensando a Escola na Era da Informática. Porto Alegre, Artes Médicas, 210 pp.

Seminério, F. L. P., et al. (1979) "O imaginário cognitivo: uma fronteira entre consciência e inconsciente." Arq. Bras. Psicol.,49.4: 94-107. 